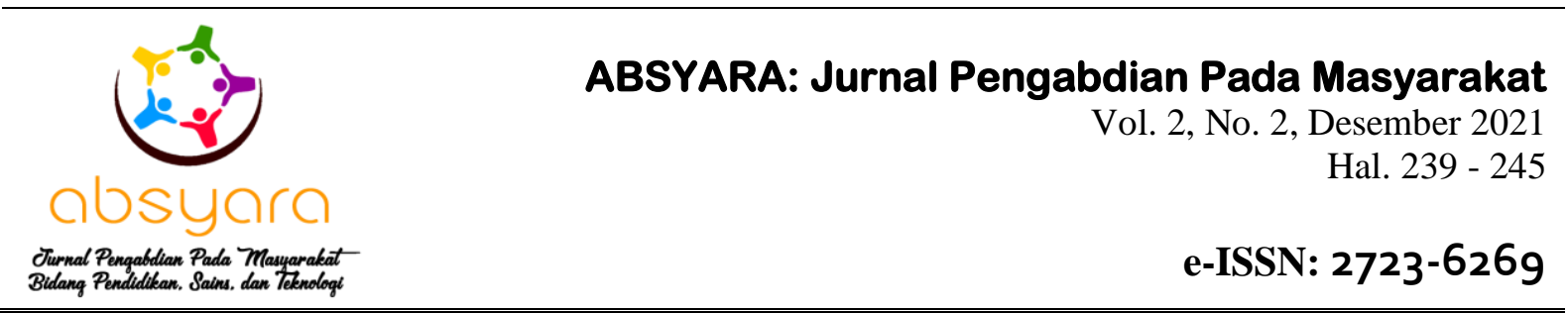

\title{
Pendampingan Perancangan Ruang Pamer Museum dr.AK.Gani pada Pameran Bersama Museum Negeri Sumatera Selatan
}

\author{
Shinta Puspasari \\ shinta@uigm.ac.id \\ Program Studi Teknik Informatika, Fakultas Ilmu Komputer, Universitas Indo Global Mandiri
}

Received: 01 November 2021 Accepted: 06 December 2021 Online Published: 30 December 2021

DOI: 10.29408/ab.v2i2.4322

\begin{abstract}
Abstrak: Pameran yang sukses tidak terlepas dari penataan ruang pameran yang tepat. Penataan ruang pameran yang baik akan menimbulkan ketertarikan dari pengunjung pameran. Terlebih lagi apa bila pameran tersebut adalah pameran museum. Penataan pameran museum membutuhkan penataan yang lebih detail. Provinsi Sumatra Selatan mengadakan pameran bersama yang diikuti oleh berbagai museum negeri seluruh Sumatera Selatan. Karena diikuti oleh berbagai museum, maka dibutuhkan penataan ruang pameran yang bagus agar dapat menyajikan ruang tata pamer optimal sehingga menarik bagi pengunjung serta tidak kalah dari Museum lainnya pada pameran tersebut. Oleh karena itu, pengabdian ini bertujuan untuk mendampingi Museum dr.AK.Gani sebagai mitra untuk menata ruang pamerannya agar lebih optimal. Kegiatan pengabdian masyarakat yang ditawarkan pada kegiatan ini adalah pendampingan mendesain brosur informatif, dan tata pamer koleksi Kegiatan Pameran berjalan dengan baik dan aman mengikuti protokol kesehatan di masa pandemi COVID-19 dihadiri oleh berbagai kalangan baik pelajar maupun masyarakat umum. Metode kegiatan meliputi diskusi kelompok terarah, desain ruang tata pamer, dan implementasi desain ruang tata pamer efektif menghasilkan desain tata pamer Museum dr.AK.Gani yang telah diimplementasikan pada Pameran Bersama 2020 di Museum Negeri Sumatera Selatan. Hasil kegiatan pendampingan berwujud desain dan perlengkapan ruang pameran museum dr.AK.Gani efektif menjadi media informatif dan menarik bagi pengunjung ruang pamer Museum dr.AK.Gani pada pameran tersebut. Dengan desain ruang pamer yang informatif dan menarik pada pameran ini diharapkan masyarakat makin mengenal keberadaan Museum dr.AK.Gani dan tertarik berkunjung ke Museum fisik meski di masa pandemi COVID-19.
\end{abstract}

Kata kunci: Museum dr.AK.Gani; Pameran Museum; Ruang Tata Pamer;

\begin{abstract}
A successful exhibition cannot be separated from the proper arrangement of the exhibition space. A good exhibition space arrangement will generate interest from exhibition visitors. Moreover, what if the exhibition is a museum exhibition. The arrangement of museum exhibitions requires a more complex arrangement. South Sumatra Province held a joint exhibition which various state museums throughout South Sumatra attended. Because various museums attend it, a good exhibition space arrangement is needed to present an optimal exhibition space so that it is attractive to visitors and is not inferior to other museums in the exhibition. Therefore, this service aims to assist dr.AK.Gani Museum as a partner to organize its exhibition space to make it more optimal. The community service activities offered at this activity are assistance in designing informative brochures and showing off collections. Exhibition activities went well and safely following health protocols during the COVID19 pandemic, attended by various students and the general public. The activity method includes focus group discussions, exhibition room design, and effective exhibition space design implementation to produce the dr.AK.Gani Museum exhibition design has been implemented at the 2020 Joint Exhibition at the South Sumatra State Museum.
\end{abstract}

Keywords: Exhibition Room; Museum dr.AK.Gani; Museum Exhibitions; 
Puspasari, S. (2021). Pendampingan perancangan ruang pamer museum dr.AK.Gani pada pameran bersama Museum Negeri Sumatera Selatan. ABSYARA: Jurnal Pengabdian Pada Masyarakat, 2(2), 293-245. doi:10.29408/ab.v2i2.4322

\section{PENDAHULUAN}

Museum Pahlawan Nasional Mayor Jenderal TNI (Purna.) dr. A.K.Gani berdiri pada 2004 dan dikelola oleh Yayasan Hj. R.A. Masturah A.K. Gani. Mayjen. TNI (Purna) dr.AK.Gani merupakan Pahlawan Nasional yang pernah menjadi Residen Palembang pertama dan Gubernur Sumatera Selatan pertama. Beliau adalah tokoh pertempuran lima hari lima malam di Palembang melawan kolonial Belanda. Ia juga terlibat dalam merintis pembangunan Jembatan Ampera dan pabrik Pupuk Sriwijaya di Palembang. Pada Tahun 2007, dr.AK.Gani diberikan gelar Pahlawan Nasional. Museum menempati bekas rumah pribadi dr. A.K. Gani yang dibangun pada 1956. Museum Tipe C ini memiliki berbagai keterbatasan karena pengelolaan oleh yayasan dan keterbatasan dana pemeliharaan. Salah satunya tidak ada tenaga ahli Teknologi Informasi untuk mendukung pengelolaan Museum.

Permasalahan muncul pada saat Museum dr.AK.Gani diundang untuk berpartisipasi pada Pameran Bersama di Museum Negeri Sumatera Selatan yang diikuti oleh berbagai Museum di provinsi Sumatera Selatan dan sejumlah Museum Nasional yang akan dibuka langsung oleh Gubernur Sumatera Selatan H. Herman Deru. Museum dr.AK.Gani memerlukan tenaga ahli teknologi informasi yang dapat membantu desain ruang tata pamer yang informatif dan menarik bagi pengunjung (Díaz, dkk., 2015) sehingga tidak kalah menarik dengan Museum lainnya. Desain Museum yang baik akan mampu mengkomunikasikan sejarah dan mengedukasi masyarakat tentang tujuan Museum (Kristianto, dkk., 2018). Kecanggihan TIK dapat dimanfaatkan sebagai media promosi Museum sebagai tempat wisata maupun edukasi (Yanchinsu, dkk., 2020). Karena itu kepala Museum mengundang tenaga ahli yang sebelumnya pernah terlibat dalam pengembangan Museum dr.AK.Gani berbasis Teknologi Informasi dan Komunikasi yaitu aplikasi pengelolaan koleksi Museum (Puspasari \& Marnisah, 2019).

Pameran bersama dilakukan dengan cara penyampaian cerita lewat koleksi maupun media informatif lainnya dengan tujuan menjangkau kalangan yang lebih luas yang selama ini belum mengetahui keberadaan Museum di daerah khususnya Sumatera Selatan. Pameran Museum diperlukan untuk mendapatkan apresiasi dari masyarakat luas dengan tujuan edukatif (Sektiadi \& Nugrahani, 2018). Untuk itu diperlukan kegiatan pendampingan sehingga tujuan kegiatan dapat membantu masyarakat (Sundari, dkk., 2020) khususnya Museum dr.AK.Gani mencapai tujuan mengikuti pameran bersama Sumatera Selatan. Dengan pelaksanaan kegiatan pengabdian masyarakat berupa pendampingan desain ruang tata pamer yang informatif dan menarik bagi Museum pahlawan nasional dr.AK.Gani pada Pameran Bersama diharapkan dapat lebih memperkenalkan keberadaan Museum dr.Ak.Gani kepada masyarakat khususnya kota Palembang dikarenakan Pameran Bersama tersebut dihadiri oleh berbagai kalangan dan terbuka untuk umum secara gratis meskipun di masa Pandemi COVID-19 tetapi dengan menerapkan protokol kesehatan dan media pembelajaran jarak jauh berbasis TIK (Fauzi, dkk., 2020). Minat kunjungan ke Museum juga diharapkan dapat meningkat (Salim, 2018) dengan adanya informasi yang menarik terutama untuk edukasi (Samsuri, dkk., 2020) sehingga dapat berdampak pada eksistensi koleksi bersejarah Museum Pahlawan Nasional Mayjen TNI (Purna) dr.AK.Gani. 


\section{METODE PELAKSANAAN}

\section{Waktu dan Lokasi}

Museum dr. AK.Gani sebagai mitra pada kegiatan ini, turut serta dalam kegiatan Pameran Bersama yang dilaksanakan di Museum Negeri Sumatera Selatan 10-16 November 2020. Pameran ini diselenggarakan oleh Dinas Kebudayaan dan Pariwisata Provinsi Sumatera Selatan dan dibuka langsung oleh Gubernur Sumatera Selatan. Untuk memaksimalkan tata pamer museum dr.AK.Gani pada kegiatan tersebut, maka kegiatan pendampingan perancangan ruang tata pamer museum dr.AK.Gani dilakukan 6-10 November 2020 yang dimulai dengan diskusi terarah dengan museum dr.AK.Gani hingga implementasi desain tata pamer yang disepakati dilakukan di lokasi Pameran Museum Negeri Sumatera Selatan.

\section{Prosedur pelaksanaan}

1. Kelompok Diskusi Terarah

Dinas Kebudayaan dan Pariwisata Provinsi Sumatera Selatan menetapkan sejumlah aturan yang harus diikuti oleh peserta pameran termasuk Museum dr.AK. Gani lewat undangan rapat yang diikuti oleh Kepala Museum dr.AK.Gani, yaitu Ibu Priyanti Gani. Desain Tata Pamer. Kegiatan dilanjutkan dengan pembuatan desain tata pamer yang telah disepakati konsepnya pada kegiatan diskusi terarah. Desain dilakukan dengan peralatan perangkat lunak Ilustrator dan pengolah kata untuk mendesain kelengkapan tata pamer diantaranya brosur dan banner yang harus didesain untuk kemudian dicetak dan di tempatkan pada ruang pamer Museum dr. Ak Gani di Pameran Bersama Museum Sumatera Selatan 2020 sebagai media penyampaian informasi bagi pengunjung ruang pameran.

2. Implementasi Desain Tata Pamer

Hasil kegiatan desain diperoleh peralatan tata pamer diantaranya brosur untuk dibagikan kepada pengunjung sebagai media penyebaran informasi mengenai Museum dr.AK.Gani sehingga diharapkan masyarakat tertarik untuk datang berkunjung ke Museum fisik yang berlokasi di Jl. MP. Mangkunegaran No. 1 Palembang. Museum dibuka untuk umum meski di masa Pandemi COVID-19 dengan protokol kesehatan yang ketat. Pengunjung diwajibkan memakai masker dan menjaga jarak. Informasi jam operasional Museum yang di buka setiap hari kerja pukul 09.00 - 17.00 WIB serta deskripsi singkat tentang koleksi Museum dapat ditemukan pada brosur tersebut.

Peralatan yang telah siap selanjutnya mulai ditata pada ruang pameran pada hari-1 pameran bersama. Tim pelaksana kegiatan melakukan penataan sesuai dengan konsep desain tata pamer Museum dr.AK.Gani. Kegiatan penataan dilaksanakan selama satu hari penuh dari Pukul 08.00 - 16.00 WIB hingga diperoleh tata ruang pamer yang siap dipamerkan.

\section{HASIL DAN PEMBAHASAN HASIL}

Untuk menyelaraskan antara kebijakan dan kebutuhan desain tata pamer Museum dr.AK. Gani pada pameran bersama tersebut, maka dilaksanakan kelompok diskusi terarah yang diikuti oleh pelaksana kegiatan pengabdian dan Museum dr.AK.Gani. Kegiatan diskusi selain dilaksanakan di Museum dr.AK.Gani juga dilakukan di Museum Negeri Sumatera Selatan sekaligus melihat langsung lokasi ruang pameran untuk mengetahui kebutuhan desain tata pamer Museum dr.AK. Gani yang sesuai dengan situasi dan kondisi tata ruang pameran 
bersama di Museum Negeri Sumatera Selatan. Hasil kegiatan diskusi kelompok disepakati konsep desain, kegiatan, dan kebutuhan tata pamer Museum dr.AK.Gani pada Pameran Bersama Sumatera Selatan 2020 di Palembang yang sesuai dengan tujuan pameran Museum dr.AK.Gani. Konsep tata pamer dibuat dengan konsep media edukasi sekaligus promosi sehingga dapat mengajak masyarakat khususnya pelajar untuk turut serta melestarikan budaya dan sejarah (Surahman, dkk., 2020; Yuliati, dkk., 2021) khususnya berkenaan dengan pahlawan nasional Mayjen TNI (Purn) dr.AK.Gani.

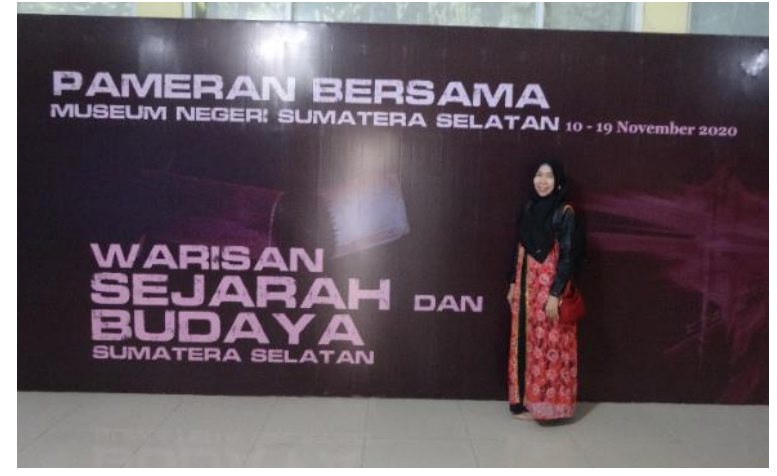

Gambar 1. Pameran Bersama Museum Negeri Sumatera Selatan 2020

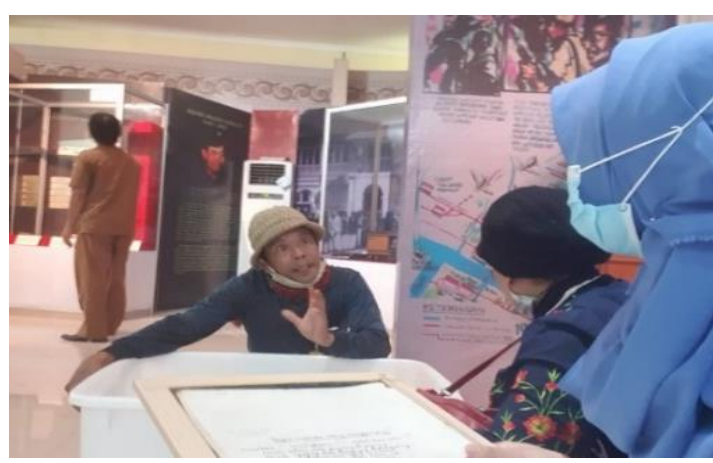

Gambar 2. Diskusi Kelompok Terarah

Kegiatan pendampingan perancangan ruang tata pamer Museum dr.AK. Gani pada pameran bersama Sumatera Selatan telah menghasilkan rancangan ruang tata pamer informatif dan menarik untuk dikunjungi masyarakat. Ruang pameran Museum dr.AK.Gani telah berhasil ditata dengan kelengkapan hasil berupa desain brosur, banner, logo museum serta perlengkapan pameran lainnya yang dirancang melalui kegiatan pendampingan ini.

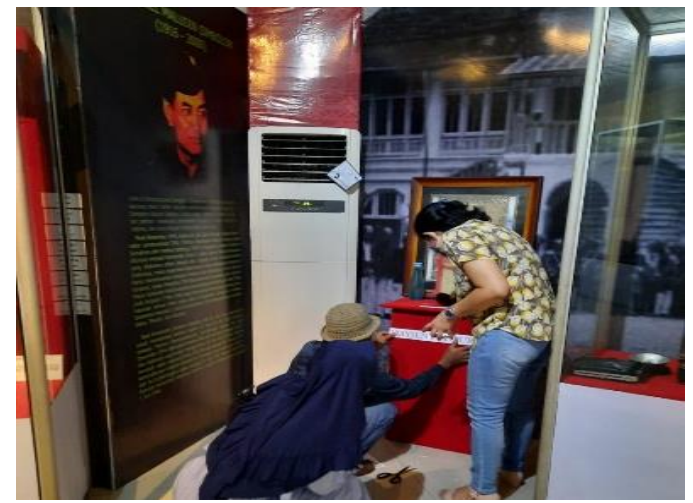

Gambar 3. Pendampingan penataan ruang pameran museum

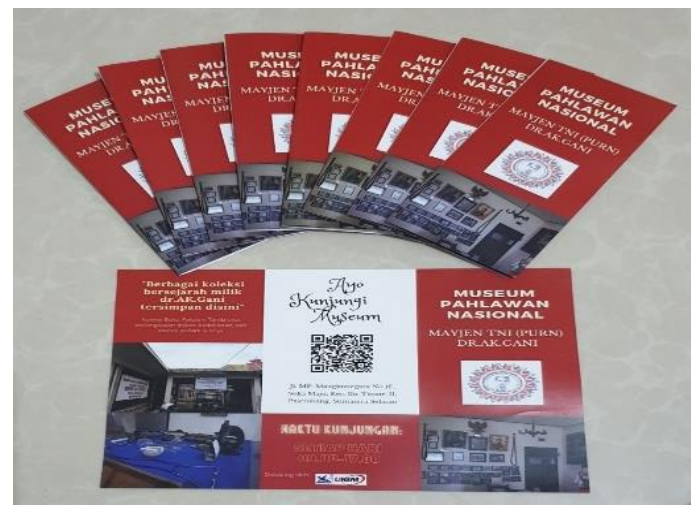

Gambar 4. Pembuatan brosur Museum dr.AK.Gani

Selanjutnya kegiatan penataan ruang pameran dilakukan di Museum Negeri Sumatera Selatan dengan didampingi langsung oleh kepala Museum dr.AK.Gani, yaitu ibu Priyanti Gani, dan hasilnya telah dipamerkan dalam Pameran Museum Bersama pada 10 - 16 November 2020. Pameran tersebut dibuka oleh Gubernur Sumatera Selatan yang dihadiri berbagai kalangan pejabat dan masyarakat. Pameran terbuka untuk umum secara gratis. Selain museum dr.AK.Gani, pameran juga diikuti oleh peserta yang merupakan museum dari berbagai daerah 
Sumatera Selatan dan juga Nasional, salah satunya Museum Basoeki Abdullah di Jakarta, yang turut memamerkan koleksi berharga museum. Pengunjung pameran bersama di Museum Negeri Sumatera Selatan tersebut berasal dari berbagai kalangan masyarakat, pelajar, dan mahasiswa serta umum dengan berbagai usia yang tertarik dengan pameran museum bersama yang menyajikan informasi seni, budaya, dan sejarah untuk tujuan edukatif sekaligus hiburan.

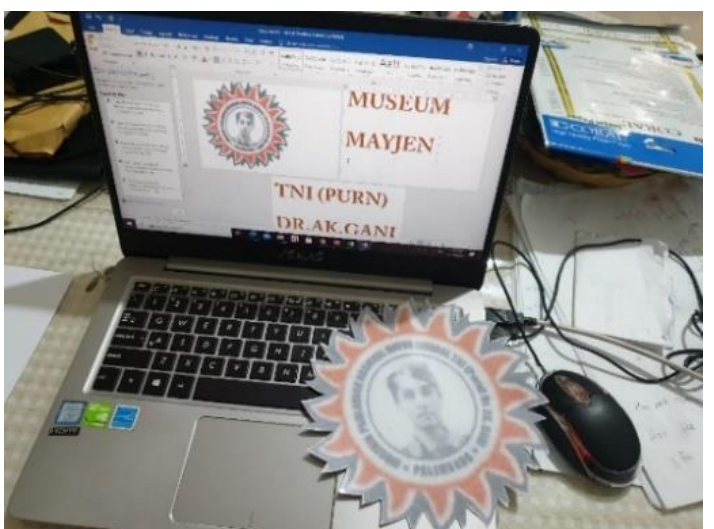

Gambar 5. Pembuatan desain banner Museum dr.AK.Gani

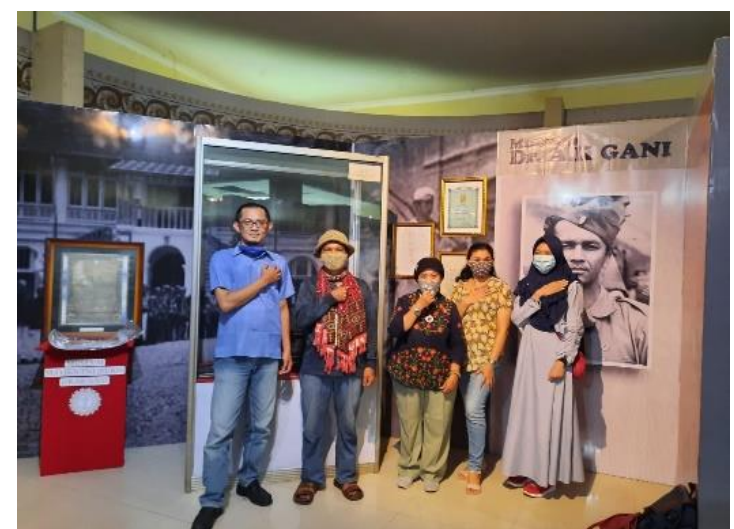

Gambar 6. Pihak Museum dr.AK.Gani di ruang pameran hasil kegiatan pendampingan

\section{PEMBAHASAN}

Kunjungan ke ruang pamer museum dr.AK.Gani ramai, lancar, dan aman dengan tetap memakai masker dan menjaga jarak antar pengunjung dengan pengawasan yang ketat dari pihak penyelenggara serta perangkat tata pamer hasil perancangan yang meminimalkan kontak langsung dengan pengunjung di masa pandemi. Perancangan ruang tata pamer dengan memanfaatkan TIK di masa pandemi COVID-19 efektif mendukung museum dr.Ak.Gani mensosialisasikan keberadaan museum lewat media tata pamer berikut kelengkapannya yang dihasilkan dari kegiatan pendampingan ini yang selaras dengan hasil kajian (Krishbie \& Dewi, 2021). Museum didesain berbasis Map atau peta yang menuntun pengunjung ke lokasi museum lewat aplikasi Google Map dengan koordinat lokasi yang tersimpan dalam QRCode. Dengan memindai QRCode pada brosur, pengguna langsung ditunjukkan rute perjalanan menuju museum dr.AK.Gani. Penjelasan ekstra harus diberikan bagi pengunjung yang awam dengan TIK sehingga desain brosur berbasis TIK yang dirancang terkesan asing dan terbatas pada data teks yang tertulis dan terlihat pada brosur padahal metadata yang tersembunyi di dalamnya tidak disadari oleh pengguna awam. Sebaliknya bagi milenial yang akrab dengan teknologi internet dan gawai pintar, pemanfaatan brosur tersebut untuk memperoleh informasi menjadi lebih interaktif dan menarik dengan menggunakan gawai yang mereka miliki.

Pemanfaatan TIK dalam desain tata pamer museum untuk optimalisasi tugas dan fungsi museum di masa pandemi (Puspasari \& Herdiansyah, 2021), efektif memberikan informasi yang menarik bagi pengunjung museum (Tjahjawulan \& Adityayoga, 2019) sekaligus media pembelajaran sejarah pahlawan nasional Mayjen. TNI (Purn) dr.AK. Gani meski terdapat pembatasan dalam pergerakan masyarakat untuk melakukan kunjungan ke museum. Masyarakat tetap dapat memperoleh informasi lewat desain tata pamer yang informatif mengenai museum pahlawan nasional dr.AK.Gani yang merupakan Gubernur Sumatera Selatan pertama meski tidak langsung berkunjung ke museum fisik. Tujuan sosialisasi museum 
fisik dr.AK.Gani lewat perancangan tata pamer informatif terwujud lewat kegiatan pengabdian ini sekaligus menjadi media pembelajaran sejarah bagi pengunjung pameran (Fitriana, dkk., 2020).

\section{SIMPULAN}

Kegiatan pengabdian masyarakat dilatarbelakangi undangan dari museum dr.AK.Gani untuk menjadi tenaga ahli yang terlibat dalam kegiatan desain tata pamer museum dr.AK.Gani pada pameran museum bersama di Museum Negeri Sumatera Selatan tahun 2020. Desain tata pamer yang diharapkan dapat menarik pengunjung serta memberikan informasi mengenai museum dr.AK.Gani mengingat situasi pandemi COVID-19 yang mengakibatkan dikeluarkan kebijakan pembatasan skala besar menuntut Museum untuk tutup sementara waktu. TIK menjadi solusi dalam mengoptimalkan peran museum di masa pandemi. Desain brosur yang diedarkan bagi pengunjung dapat menuntun pengunjung ke lokasi Museum setelah diizinkan untuk kembali dibuka untuk umum oleh pemerintah.

Metode kegiatan meliputi diskusi kelompok terarah, desain tata pamer, dan implementasi desain tata pamer efektif menghasilkan desain tata pamer Museum dr.AK.Gani yang telah diimplementasikan pada Pameran Bersama 2020 di Museum Negeri Sumatera Selatan. Pameran yang diikuti sejumlah Museum di daerah Sumatera Selatan dan Museum Nasional lainnya terbuka untuk umum dari berbagai kalangan. Perlengkapan tata pamer yang dirancang efektif menjadi media informatif dan menarik bagi pengunjung ruang pamer Museum dr.AK.Gani pada pameran tersebut. Brosur yang menarik dan interaktif dapat dimanfaatkan sebagai media informatif yang menuntun pengunjung ke lokasi Museum dr.AK.Gani lewat bantuan aplikasi Google Map. Pandemi COVID-19 menuntut Museum untuk berinovasi memanfaatkan TIK untuk mempromosikan koleksi Museum meski dibatasi ruang dan jarak. Diharapkan kegiatan ini dapat berdampak pada eksistensi Museum dr.AK.Gani di masa pandemi COVID-19 menuju masa kebiasaan baru.

\section{PERNYATAAN PENULIS}

Artikel ini tidak pernah dimuat dalam jurnal pengabdian maupun jurnal penelitian sebelumnya.

\section{DAFTAR PUSTAKA}

Díaz, P., Bellucci, A., \& Aedo, I. (2015). Enabling social interaction in the museum through the social display environment. In 2015 Digital Heritage (Vol. 1, pp. 345-348). IEEE.

Fauzi, L. M., Supiyati, S., \& Rasidi, A. (2020). Workshop Distance Learning Di Masa Pandemic Covid 19. ABSYARA: Jurnal Pengabdian Pada Masyarakat, 1(1), 16-21.

Fitriana, R., Rahmitasari, N., \& Yoseli, M. (2020). Analisis Motivasi Pengunjung Museum Macan Jakarta. Jurnal Ilmiah Pariwisata, 25(1), 76-83.

Kristianto, T. A., Ardianto, O. P. S., Budianto, C. A., \& Rahayu, S. (2018). Interior Pencerita, Kolaborasi Grafis Visual dan Desain Interior pada Perancangan Interior Museum "Rumah Air" PDAM Surya Sembada Surabaya. Jurnal Desain Interior, 3(2), 11-26.

Krishbie, B. G., \& Dewi, C. S. (2021). Tantangan Museum Seni di tengah Pandemi Covid-19 Kajian: Pameran Imersif Affandi di GNI, 2020. Jurnal Senirupa Warna, 9(2). 
Puspasari, S. (2021). Pendampingan perancangan ruang pamer museum dr.AK.Gani pada pameran bersama Museum Negeri Sumatera Selatan. ABSYARA: Jurnal Pengabdian Pada Masyarakat, 2(2), 293-245. doi:10.29408/ab.v2i2.4322

Puspasari, S., \& Herdiansyah, M. I. Pengenalan Teknologi Augmented Reality untuk Media Edukasi Koleksi Museum SMB II di Masa Pandemi Covid-19. Bakti Budaya: Jurnal Pengabdian kepada Masyarakat, 4(2), 143-151.

Puspasari, S., \& Marnisah, L. (2019). Implementasi E-Museum Dr. AK. Gani Palembang. Jurnal Abdimas Mandiri, 3(2), 120-130.

Salim, P. (2018). Persepsi Kualitas Ruang Pamer Museum Seni: sebuah Studi Observasi. Narada, 5(1), 25-34.

Samsuri, T., Muliadi, A., Muhali, M., Asy'ari, M., Prayogi, S., \& Hunaepi, H. (2020). Pelatihan desain media interaktif pada pembelajaran daring bagi dosen pendidikan biologi. ABSYARA: Jurnal Pengabdian Pada Masyarakat, 1(2), 64-69.

Sektiadi, S., \& Nugrahani, D. S. Pemberdayaan Masyarakat di Sekitar Cagar Budaya Melalui Pameran Museum. Bakti Budaya: Jurnal Pengabdian kepada Masyarakat, 1(1), 57-64.

Sundari, S., Taher, D. M., Nurhasanah, N., Mas' ud, A., \& Hasan, S. (2020). Pendampingan pembuatan hand sanitizer berbasis kearifan lokal (ekstrak tangkai bunga cengkeh). ABSYARA: Jurnal Pengabdian Pada Masyarakat, 1(2), 49-55.

Surahman, M., Sugiyanto, S., DRUPADI, R. D., \& Pangestu, D. (2020). Pemanfaatan Museum dalam Pelestarian Budaya Daerah Lampung Sebagai Upaya Pengembangan Media Pembelajaran Guru Sekolah Dasar. Jurnal Pemberdayaan: Publikasi Hasil Pengabdian kepada Masyarakat, 4(3), 279-282.

Tjahjawulan, I., \& Adityayoga, A. (2019). Penyajian Koleksi Museum Sejarah dan Budaya Kota Malang. JSRW (Jurnal Senirupa Warna), 7(2), 1-20.

Yanchinsu, V. N., Pratiwi, P., \& Wenas, M. B. (2020). Perancangan Video Panduan Museum Kars Indonesia. Prabangkara: Jurnal Seni Rupa dan Desain, 24(2), 95-105.

Yuliatin, R. R., Dewi, P., Arianti, B. D. D., \& Murcahyanto, H. (2021). Pengenalan Object Theatre pada remaja Bremi Lombok Timur. ABSYARA: Jurnal Pengabdian Pada Masyarakat, 2(1), 109-118. 